\title{
Study of cord blood albumin as a predictor of neonatal jaundice
}

\author{
Pabitra Sapkota ${ }^{1}$, Fakir Chandra Gami² \\ ${ }^{1}$ General Pediatrician, Matri Shishu Miteri Hospital, Pokhara, Nepal, ${ }^{2}$ Professor of Pediatrics, Department of Pediatrics, \\ Nepal Medical College Teaching Hospital, Kathmandu, Nepal
}

Background: Neonatal jaundice is a commonly encountered condition in the neonates during first week of life. Early discharge of healthy term newborns is a common practice, because of the risk of nosocomial infections, social causes like in early naming ceremony, and also due to economical constrains. In significant number of newborns, neonatal hyperbilirubinemiais the most common cause for readmission. There is concern regarding early discharge of healthy term newborns due to reports of bilirubin induced brain damage resulting in sequel like kernicterus .There are reports of bilirubin induced brain damage which occurred in healthy term neonates even without hemolysis and the clinical outcome could be serious. The need for early detection of hyperbilirubinemia in the newborns is therefore important. Aims and Objective: The objective of the study was to find whether cord blood albumin can be considered as a predictor of neonatal jaundice. The study also explored for any possible associations of different factors like gender, birth weight and mode of delivery with the occurrence of neonatal jaundice. Materials and Methods: The hospital based cross sectional study enrolled 100 healthy term newborns from August 2016-July 2017. Cord blood was sent for albumin level and blood group estimation. All babies were assessed for clinical jaundice using Krammer criteria and confirmed by estimation of total serum bilirubin level on the fourth day of life. Results: Correlation of cord blood albumin with the fourth day bilirubin level revealed negative correlation ( $r$ value of 0.455 ) with $p$ value of 0.000 which was highly significant. However, there was no correlation between cord blood albumin level with total serum bilirubin level of more than $17 \mathrm{mg} / \mathrm{dl}$ (neonatal hyperbilirubinemia) that required phototherapy or exchange transfusion ( $p$ value of $>0.005$ ) Similarly, the study found no statistically significant association of neonatal jaundice with gender, weight and mode of delivery of the neonates. Conclusion: Cord blood albumin can be a risk factor rather than a diagnostic tool which can give a clue to possibility of high bilirubin level during neonatal period. There was no statistical significance seen between cord blood albumin level with total serum bilirubin level of $\geq 17 \mathrm{mg} / \mathrm{dl}$ (neonatal hyperbilirubinemia) that required phototherapy or exchange transfusion.
Access this article online

Website:

http://nepjol.info/index.php/AJMS

DOI: $10.3126 /$ ajms.v11i4.29198

E-ISSN: 2091-0576

P-ISSN: 2467-9100

Copyright (c) 2020 Asian Journal of Medical Sciences

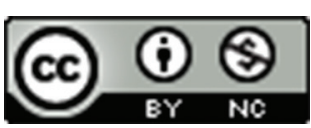

This work is licensed under a Creative Commons Attribution-NonCommercial 4.0 International License.

Key words:Cord blood albumin level; Neonatal Hyperbilirubinemia

\section{INTRODUCTION}

There is a concern of pediatrician regarding the early discharge due to reports of bilirubin induced brain damage occurring in healthy term infants even without hemolysis. The neurological effect may result in serious conditions like cerebral palsy, sensorineural deafness and mental retardation. ${ }^{1}$

The treatment of severe neonatal hyperbilirubinemia $(\mathrm{NH})$ by exchange transfusion is costly. It is associated with complications, time consuming and requires skilled manpower. Early detection of risk factors is the first step towards prevention of $\mathrm{NH}$ and a step ahead in protecting newborns from complication at later age. Besides, this early treatment of jaundice with phototherapy is effective, simple and cheap.

American Academy of pediatrics (AAP) recommended the use of total serum bilirubin level over albumin ratio (TSB/A) in addition to the total bilirubin level in the 
management of neonatal jaundice. Even though they assumed the ratio as a rough measure of bilirubin binding albumin, it has not been widely used clinically. Pediatrician are encouraged to measure the albumin level along with total bilirubin concentration. A lower than expected albumin concentration may even alert the pediatrician to the possible need for intervention at lower than usual total bilirubin concentration. ${ }^{2}$

There have not been many studies regarding cord blood albumin levels as a predictor of neonatal jaundice. The present study is conducted to find out any association of cord blood albumin in predicting the subsequent development of neonatal jaundice and requirement of interventions like phototherapy or exchange transfusion. This could help in identifying the babies requiring intervention and those who do not. Thus, we could more flexibly plan an early discharge of the neonate or anticipate and prepare for phototherapy or exchange transfusion. The main objective of the study was to measure cord blood albumin as predictor of neonatal jaundice among Nepalese population. The study also aimed to predict interventions like phototherapy and exchange transfusion based on the level of cord albumin and plan early intervention. In addition, the study also looked into any possible associations of gender, birth weight and mode of delivery with cord blood albumin and total serum bilirubin level.

\section{MATERIALS AND METHODS}

The hospital based cross sectional study enrolled 100 neonates into the study from thelabor room, obstetric operation theatre, maternity ward and the pediatric outpatient department of Nepal Medical College Teaching Hospital for a period of one year (August 2016-July 2017).

The inclusion criteria for the study werethe term neonates delivered by the normal vaginal delivery or cesarean sectionwith1 minAPGAR score ofmore than 7 . The exclusion criteria were neonates with $\mathrm{ABO} / \mathrm{Rh}$ incompatibility, 1 minutes APGAR score of equal to or less than 7, instrumental delivery (forceps and vacuum), suspected or proven sepsis, congenital anomalies and preterm babies.

An informed consent was obtained from the parents of the neonates before enrolling them in the study. Relevant information was collected by using structured proforma by interviewing the mother and from mother's case sheet. Cord blood albumin level and blood group was estimated at birth.All the babies were followed up for jaundice and total serum bilirubin (TSB) estimation was done on fourth day of life (after 72 hours of life).Data with regards to clinical jaundice was assessed using Krammercriteria ${ }^{3}$ on days 3 to 5 and total serum bilirubin estimation was done with venous blood of neonates.

Cord blood collected at birth was analyzed for albumin level by automated dry chemistry equipment (VITROS 250 CHEMISTRY) for albumin estimation.After 72 hours, venous blood sample was collected and sent to laboratory immediately for total serum bilirubin estimation. The sample which could not be immediately test were stored in a refrigerator between $2-8$ degree Celsius. Serum bilirubin was measured using automated dry chemistry equipment (VITROS 250 CHEMISTRY). Blood group of neonates were analyzed by antisera method.

\section{Inference}

Serum bilirubin $\geq 17 \mathrm{mg} / \mathrm{dl}$ after 72 hours of life was taken as neonatal hyperbilirubinemia and treatment is advised, as per the American academy of pediatrics practice parameter, $2004 .{ }^{4}$

Indian Academy of Pediatrics-National Neonatology Forum also recommends considering phototherapy with neonatal total serum bilirubin level of $\geq 17 \mathrm{mg} / \mathrm{dl}$ after 72 hours of life. ${ }^{5}$ So, in the study neonates with total serum bilirubin level of $\geq 17 \mathrm{mg} / \mathrm{dl}$ were considered as having hyperbilirubinemia and needed intervention (like phototherapy or exchange transfusion) after 72 hours of postnatal life.

\section{Ethics}

Ethical approval from the institute review board was taken. Parent's written consent was taken for each baby before participation in the studies.

\section{Statistics}

Data was analyzed using bivariate correlation done for continuous variables like cord blood albumin and serum bilirubin level. Chi-square test was done for finding association between two or more categorical variables. Data was collected, compiled and analyzed by using software SPSS 16.0.

\section{RESULTS}

\section{Characteristics of neonates}

The neonates included in the study were 67 male and 33 female. Seventy neonates were delivered by normal vaginal delivery (NVD) and 30 were by lower uterine segment caesarean section (LUCS). Out of those 100 neonates, 10 neonates weighed $<2.6 \mathrm{~kg}$, 73 neonates weighed between 2.6 to $3.5 \mathrm{~kg}$ and 17 neonates weighed $>3.5 \mathrm{~kg}$. Neonates with $\mathrm{ABO}$ incompatibility with mothers were excluded from the study. Majority (42\%) of mother belonged to A positive blood group, followed by B positive with $27 \%$, O 
positive with $25 \%$ and $\mathrm{AB}$ positive with $6 \%$.Blood group A $(48 \%)$ was the most common blood group of neonates followed by $\mathrm{B}$ positive $(26 \%)$, $\mathrm{O}$ positive $(19 \%)$ and $\mathrm{AB}$ positive $(7 \%)$.

\section{Cord blood albumin level of the neonates}

Cord blood albumin results were grouped into three categories. Group 1 was comprised of $20 \%$ of neonates with cord albumin level $<2.9 \mathrm{gm} / \mathrm{dl}$, group 2 had $47 \%$ of neonates with cord albumin level between 2.9 to $3.5 \mathrm{gm} / \mathrm{dl}$ and group 3 had $33 \%$ of neonates with cord albumin level $>3.5 \mathrm{mg} / \mathrm{dl}$.

\section{Fourth day total serum bilirubin level}

On fourth day of life (after 72 hours of life) venous blood was collected for bilirubin level and were grouped into three categories. Group $1(10 \%)$ was comprised of the neonates with serum bilirubin level $\leq 7 \mathrm{mg} / \mathrm{dl}$, group $2(85 \%)$ had serum bilirubin level between 7 to $17 \mathrm{mg} / \mathrm{dl}$ and group 3 $(5 \%)$ had serum bilirubin $\geq 17 \mathrm{mg} / \mathrm{dl}$.

\section{Neonates requiring Phototherapy}

5 out of 100 newborns in the study developed significant neonatal hyperbilirubinemia requiring phototherapy i.e. (total serum bilirubin level $\geq 17 \mathrm{mg} / \mathrm{dl}$ ). None of the neonates required exchange transfusion.

Comparison of gender and cord blood albumin level The study did not find any statistically significant association of gender with cord blood albumin level $(\mathrm{p}=0.245)$. Thus, the study showed that there is no correlation between the gender and the cord blood albumin level.

\section{Birth weight and cord blood albumin correlation}

The study also looked for any association between birth weight and cord blood albumin level. Statistical association was measured with pearson chi square test and with a $p$ value of 0.472 and was not statistically significant. However, a poor positive correlation between cord blood albumin level and birth weight was observed ( $r$ value of 0.073 ) as shown in Figure 1. This revealed slight increase in birth weight (0.06 times) with the increase in cord albumin level. Hence, negligible positive co-relation between the birth weight and cord blood albumin level of neonates was observed.

\section{Comparison between phototherapy and cord blood} albumin level

Cord blood albumin group of $<2.9 \mathrm{gm} / \mathrm{dl}$ had 20 neonates out of which $1(5 \%)$ required phototherapy whereas $19(95 \%)$ did not require any intervention. 47 neonates belonged to cord blood albumin group of $2.9-3.5 \mathrm{gm} / \mathrm{dl}$ in which 3(6.3\%) required phototherapy. Similarly, of 33 neonates who belonged to albumin group of $>3.5 \mathrm{gm} / \mathrm{dl}$ group, $1(3 \%)$ needed phototherapy. Out of 5 neonates who

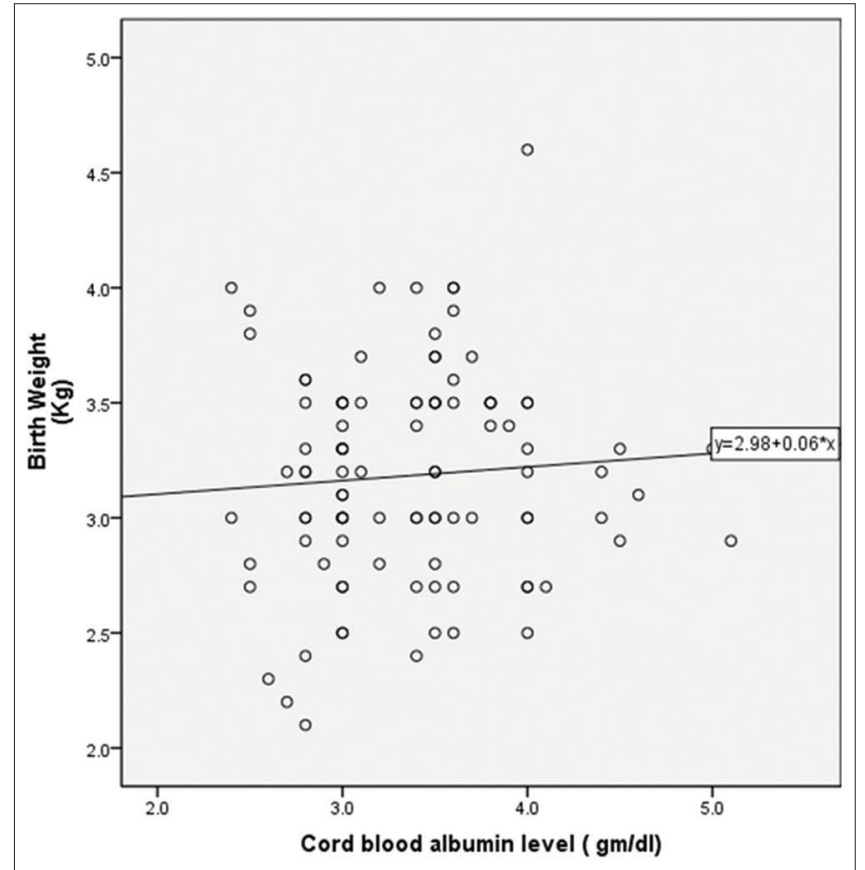

Figure 1: Scatter graph of birth weight and cord albumin level

required phototherapy, $1(20 \%)$ belonged to $<2.9 \mathrm{gm} / \mathrm{dl}$ group, $3(60 \%)$ belonged to 2.9 to $3.5 \mathrm{gm} / \mathrm{dl}$ group and 1 $(20 \%)$ belonged to $>3.5 \mathrm{gm} / \mathrm{dl}$ group.

The association between need of phototherapy for neonatal hyperbilirubinemia with cord blood albumin level was studied and was found to be insignificant with $\mathrm{p}$ value of 0.784 . Thus, this study concluded that there is no association between the cord blood albumin level and the need for phototherapy for neonatal hyperbilirubinemia.

\section{Correlation of cord blood albumin with the} fourth day bilirubin

In cord blood albumin group of $<2.9 \mathrm{gm} / \mathrm{dl}$, out of 20 neonates, none had fourth day bilirubin $\leq 7 \mathrm{mg} / \mathrm{dl}, 19$ $(95 \%)$ had bilirubin $7-17 \mathrm{mg} / \mathrm{dl}$ and $5 \%$ (1) had bilirubin level $\geq 17 \mathrm{mg} / \mathrm{dl}$. In albumin group of $2.9-3.5 \mathrm{gm} / \mathrm{dl}$, out of 47 neonates, $2(4.3 \%)$ had bilirubin $\leq 7 \mathrm{mg} / \mathrm{dl}, 42(89.4 \%)$ had bilirubin $7-17 \mathrm{mg} / \mathrm{dl}$ and $3(6.3 \%)$ had bilirubin level $\geq 17 \mathrm{mg} / \mathrm{dl} . \mathrm{In}$ albumin group of $>3.5 \mathrm{gm} / \mathrm{dl}$, out of 33 neonates, 8 (24.2\%) had bilirubin $\leq 7 \mathrm{mg} / \mathrm{dl}, 24(72.7 \%)$ had bilirubin $7-17 \mathrm{mg} / \mathrm{dl}$ and $1(3.1 \%)$ had bilirubin level $\geq 17 \mathrm{mg} / \mathrm{dl}$.

All of the neonates with cord blood albumin level $<2.9 \mathrm{gm} / \mathrm{dl}$, developed clinical jaundice i.e. bilirubin level $\geq 7 \mathrm{mg} / \mathrm{dl}$ on fourth day, whereas $4.3 \%$ of neonates in cord blood albumin level 2.9 to $3.5 \mathrm{gm} / \mathrm{dl}$ did not develop jaundice and $24.2 \%$ neonates with cord blood albumin level $>3.5 \mathrm{gm} /$ $\mathrm{dl}$ did not develop jaundice. Hence, correlation of cord blood albumin with the fourth day bilirubin levelshowed negative 


\begin{tabular}{|c|c|c|c|c|c|}
\hline \multirow[t]{2}{*}{ Variables } & \multicolumn{5}{|c|}{ Bilirubin level } \\
\hline & Group1 ( $\leq 7 \mathrm{mg} / \mathrm{dl})$ & Group2 (7-17mg/dl) & Group3 ( $\geq 17 \mathrm{mg} / \mathrm{dl})$ & Total & $P$ value \\
\hline 1.Gender & & & & & .0189 \\
\hline Male & $7(10.5 \%)$ & $58(86.5 \%)$ & $2(3.0 \%)$ & $67(100.0 \%)$ & \\
\hline Female & $3(9.0 \%)$ & $27(82.0 \%)$ & $3(9.0 \%)$ & $33(100.0 \%)$ & \\
\hline 2.Mode of delivery & & & & & 0.956 \\
\hline NVD & $7(10.0 \%)$ & $60(85.7 \%)$ & $3(4.3 \%)$ & $70(100.0 \%)$ & \\
\hline LSCS & $3(10.0 \%)$ & $25(83.3 \%)$ & $2(6.7 \%)$ & $30(100.0)$ & \\
\hline 3.Birth weight(kg) & & & & & 0.386 \\
\hline Group $1(<2,6)$ & $0(0.0 \%)$ & $10(100.0 \%)$ & $0(5.0 \%)$ & $10(100.0 \%)$ & \\
\hline Group 2 (2.6-3.5) & $9(12.3 \%)$ & $61(83.6 \%)$ & $3(4.1 \%)$ & $73(100.0 \%)$ & \\
\hline Group 3(>3.5) & $1(5.9 \%)$ & $14(82.3 \%)$ & $2(11.8 \%)$ & $17(100.0 \%)$ & \\
\hline
\end{tabular}

correlation $(r=-0.447)$ as shown in Figure 2. With per unit increase in cord albumin level, bilirubin level decreased by 2.26 times .Thus, higher the albumin level, lower was the bilirubin level and lower the albumin level higher was the bilirubin level ( $p$ value of $<0.001$ ).

Association of different variables with total serum bilirubin level

This Table 1 shows the correlation of variables like gender, mode of delivery, birth weight with total serum bilirubin level. There was no statistical significance seen between these variables with total serum bilirubin level.

Association of different variables with phototherapy

The correlation of variables like gender, mode of delivery, cord blood albumin level, birth weight with neonates who developed $\mathrm{NH}$ requiring phototherapy revealed no statistical significance.

\section{DISCUSSION}

Neonatal hyperbilirubinemia is one of the most common causes for readmission of the newborns. The need for early detection of hyperbilirubinemia in the early discharged newborns from the hospital is hence important. Knowledge of the neonates at risk for developing jaundice is the first step towards prevention of $\mathrm{NH}$ and a step ahead in protecting newborns from complication at later age. This study explored whether the cord blood albumin level can be a tool for screening the risk of neonatal jaundice.

The study did not find any statistically significant association of gender and cord blood albumin level ( $p$ value of 0.245 ). Also, no statistically significant $(\mathrm{p}=0.472)$ association of the birth weight of neonates with the cord blood albumin level was observed. A poor positive correlation between cord blood albumin level and birth weight ( $\mathrm{r}$ value of 0.073 ) was obtained. There was slight increase in birth weight (0.06 times) with increase in cord albumin level. Thus, a negligible positive co-relation was

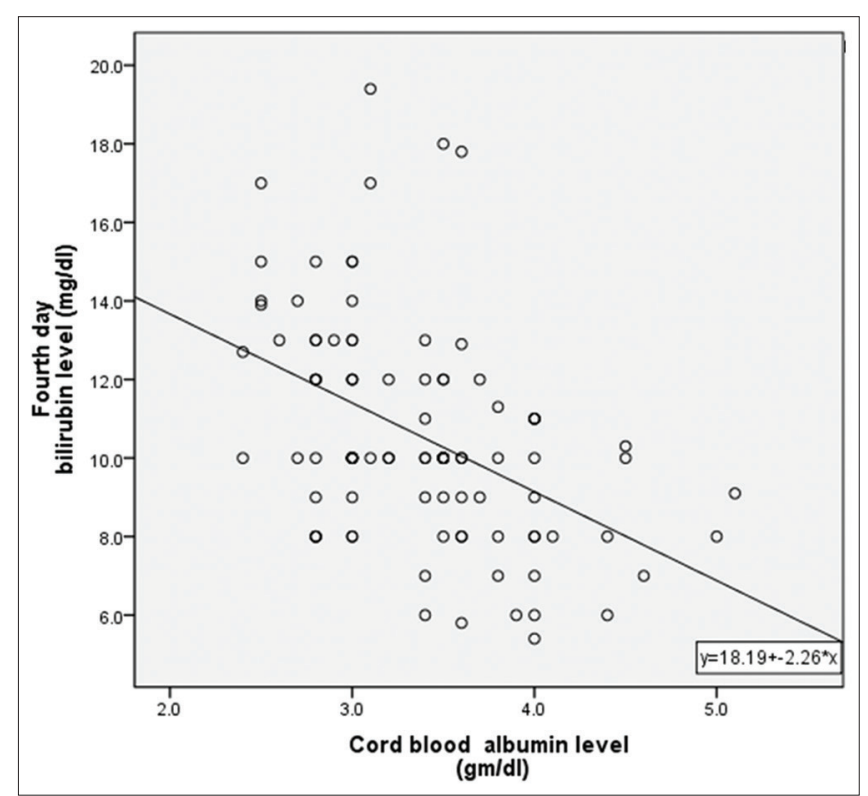

Figure 2: Scatter graph of cord blood albumin and fourth day bilirubin level

obtained between the birth weight and cord blood albumin level of neonates. However, in the studies by Knusdenetal ${ }^{6}$ and Awathi and Rehman ${ }^{7}$, no significant correlation between the birth weight and cord blood albumin level was found.

The association between need of phototherapy for neonatal hyperbilirubinemia with cord blood albumin level was found to be insignificant ( $p=0.784)$. Thus, the study did not find any association between the cord blood albumin level and the need for phototherapy for neonatal hyperbilirubinemia.

Correlation of cord blood albumin level with total serum bilirubin level

The study looked into any possible association between cord blood albumin level and the fourth day serum bilirubin. Correlation of cord blood albumin with fourth day bilirubin levelshowed negative correlation ( $r=-0.447)$. With per unit increase in cord albumin level, bilirubin level decreased by 2.26 times. Thus, the study concluded 
that higher the albumin level, lower is the bilirubin level and lower the albumin level higher is the bilirubin level $(p=<0.001)$. Thus, higher the cord blood albumin level, fourth day serum bilirubin was found to be on lower side. With this finding, cord blood albumin may be considered as a risk factor for neonatal jaundice. This result is similar to the findings by Trivedi et $\mathrm{al}^{8}$ which showed negative correlation $(r=-0.1917)$ of cord serum albumin levels with bilirubin level thereby concluding cord serum albumin level as a risk indicator in predicting neonatal hyperbilirubinemia.

It is interesting to note that lower level of serum albumin at birth definitely correlated with higher level of total serumbilirubin. Thus, cord blood albumin can be considered as a risk factor rather than a diagnostic tool, which can give a clue to the possibility of severe jaundice during neonatal period. It may help the treating doctor and the parents to stay alert and take action at the earliest. Thus, it can be a useful tool in preventing Kernicterus or any other forms of toxicity due to hyperbilirubinemia.

Comparison of gender association with total serum bilirubin

The study did not find a significant correlation of the total serum bilirubin levels and the gender of the neonates $(p=0.189)$.Similarly, the present study also revealed that the neonatal serum hyperbilirubinemia $(\geq 17 \mathrm{mg} / \mathrm{dl}$ i.e. serum bilirubin requiring phototherapy or exchange transfusion is independent of the gender of the newborn $(p=0.192)$. The study is congruent to the findings of of the study by Amar Taksande et $\mathrm{al}^{9}$ on 200 neonates with 82 males and118 females. 8 males and 11 females had serum bilirubin level of $(\geq 17 \mathrm{mg} / \mathrm{dl})$ with $\mathrm{p}$ value of 0.323 . They found no correlation between the gender of the newborn and the neonatal hyperbilirubinemia ( $\geq 17 \mathrm{mg} / \mathrm{dl}$ ). The study finding is however in contrast to the findings by RudySatrya et $\mathrm{al}^{10}$ who observed a significant correlation between the gender of the neonates and neonatal hyperbilirubinemia with $\mathrm{p}<0.05$. Of 88 newborns included in the study, 21developed hyperbilirubinemia of which 16 were males and 5 females.

Similarly, Trivedi et $\mathrm{al}^{8}$ concluded male babies had higherincidence of developing hyperbilirubinemia than female in a study which consisted of 605 newborn, 305 male and 300 female. Neonatal hyperbilirubinemia developed in 115 male and 90 female.Maisal et $\mathrm{al}^{11}$ in a study consisting of 29934 infants looked for the factorsassociated with readmission for jaundice. Male sex in the study group was $74.8 \%$ compared to control with $49.6 \%$, with p value 0.007 , showing that male sex has morerisk of readmission for neonatal hyperbilirubinemia.
Comparison of mode of delivery with total serum bilirubin level

In the study, association between the total serum bilirubin level and the mode of delivery was also looked. The study revealed no association between the neonatal hyperbilirubinemia $(\geq 17 \mathrm{mg} / \mathrm{dl})$ and the mode of the delivery $(p=0.621)$.

Amar Taksande et $\mathrm{al}^{9}$, in their study on 200 newborns, found 11 cases of 114 vaginal delivery and 8 cases of 66 caesarean section developed significant hyperbilirubinemia. With p value of 0.527 , the study showed no correlation between the mode of delivery and neonatal hyperbilirubinemia. Similarly, Rudy Satrya et al in $2009^{10}$ in a study on 88 newborns, with cut off neonatal hyperbilirubinemia of $\geq 14.9 \mathrm{mg} / \mathrm{dl}$, showed that there is no association ( $p$ value 0.885 ) between the mode of delivery and neonatal hyperbilirubinemia.Taksande et $\mathrm{al}^{9}$, Satrya et $\mathrm{al}^{10}$ also concluded that there was no significant association between the mode of delivery and neonatal hyperbilirubinemia.

Comparison of birth weight with total serum bilirubin level

The study did not find significant association between birth weight and neonates developing jaundice $(p=0.386)$. This finding was similar to the studies by Sun $\mathrm{G}$ et al ${ }^{12}$ and Sahu et $\mathrm{al}^{13}$ where no correlation between the neonatal hyperbilirubinemia and the birth weight of the newborn $(p>0.05)$ was observed.

Similarly, out of 10 neonates in the group 1(birth weight $<2.6 \mathrm{~kg}$ ) none required phototherapy. 73 neonates of the group 2 (birth weight 2.6 to $3.5 \mathrm{~kg}$ ) 3(4.1\%) required phototherapy and 17 neonates of the group 3 (birth weight $>3.5 \mathrm{~kg}) 2(11.8 \%)$ required phototherapy. Statistical correlation was not seen between the neonates requiring phototherapy for hyperbilirubinemia and the birth weight of the newborn ( $p$ value of 0.113 ).

\section{CONCLUSION}

The study found negative correlation between cord blood albumin level and fourth day total serum bilirubin level of neonates. The neonates with high cord blood albumin level had lower level of total serum bilirubin (pearson correlation test, $\mathrm{r}=-0.455, \mathrm{p}=0.000$ ). Thus, cord blood albumin can be considered as a predictor of neonatal jaundice. However, there is no statistical relation of cord blood albumin level with total serum bilirubin level of more than $17 \mathrm{mg} / \mathrm{dl}$ (neonatal hyperbilirubinemia) that required phototherapy or exchange transfusion. This may be due to small sample size of neonates who had bilirubin level $\geq 17 \mathrm{mg} / \mathrm{dl}$. With large sample size, we may get an association. 
Cord blood albumin can be considered as a risk factor rather than a diagnostic tool, which can give a clue to the possibility of severe jaundice during neonatal period. It may help the treating doctors and the parents stay alert to take action at the earliest. Thus, it can be a useful tool in preventing kernicterus or any other forms of toxicity due to hyperbilirubinemia.The study found no statistically significant association of neonatal jaundice with gender, weight and mode of delivery of the neonates.

\section{LIMITATIONS OF THE STUDY}

The study had a number of limitations. It was carried out in a small number of neonates. Many neonates mostly those who were delivered by normal vaginal deliveries were lost to follow up for bilirubin assessment after 72 hours of life and thus, only 100 neonates were available for the study. It was difficult to convince parents to return to the hospital after discharge for a bilirubin measurement.

The study could only establish a negative correlation of cord blood albumin with serum bilirubin level. There were only had 5 neonates with neonatal hyperbilirubinemia (bilirubin $\geq 17 \mathrm{mg} / \mathrm{dl}$ ). If the study had large number of neonates with neonatal hyperbilirubinemia, possibly the association of cord blood albumin with neonatal hyperbilirubinemia could be explored. The data from such small number of samples in the study may not yield a conclusive evidence.

The neonates selected for the study were full term and preterm neonates and neonates with other co-morbidities were excluded.

\section{ACKNOWLEDGEMENT}

The authors take this opportunity to thank Department of Pediatrics, Nepal Medical College Teaching Hospital, and Kathmandu for the immense support and contribution to carry out the research.

\section{REFERENCES}

1. MaiselsMJ and Newman TB. Kernicterus in Otherwise Healthy, Breast-fed Term Newborns. Pediatrics. 1995 Oct 1; 96(4):730.

2. Newman TB, Escobar GJ, Gonzales VM, Armstrong MA, Gardner MN AND Folck BF. Frequency of neonatal bilirubin testing and hyperbilirubinemia in a large health maintenance organization [published correction appears in Pediatrics 2001 Mar-Apr;1(2):126]. Pediatrics. 1999;104(5 Pt 2):1198-1203..

3. Kramer LI. Advancement of dermal icterus in the jaundiced newborn. Am J Dis Child. 1969 Sep 1; 118(3):454-8. https://doi.org/10.1001/archpedi.1969.02100040456007

4. American Academy of Pediatrics.Clinical Practice Guideline. Subcommitte on Hyperbilirubinemia: Management of Hyperbilirubinemia in the Newborn Infant 35 or More Weeks of Gestation. Am AcadPediatr. 2004 Jul;114:297-316.

https://doi.org/10.1542/peds.114.1.297

5. G G, Chawla D, Aggarwal S. Management of neonatal hyperbilirubinemia. NNFClinPractGuidel2010; Available from: http :// nnfpublication.org/

6. Knudsen A. Prediction of the development of neonatal jaundice by increased umbilical cord blood bilirubin. ActaPaediatr Scand. 1989 Mar;78(2):217-21. https://doi.org/10.1111/j.1651-2227.1989.tb11059.x

7. Awasthi $S$ and Rehman $H$. Early prediction of neonatal hyperbilirubinemia. Indian J Pediatr. 1998 Feb; 65(1):131-9. https://doi.org/10.1007/BF02849704

8. Trivedi Dj, Markande D M, Bhat M and Hegde Pr. Cord Serum Bilirubin and Albumin in Neonatal Hyperbilirubinemia. Int $\mathrm{J}$ IntegrScilnnov Technol. 2013 Apr; 2(2):39-42.

9. Taksande A, Vilhekar K, Jain M and Zade P. Prediction of the development of neonatal hyperbilirubinemia by increased umbilical cord blood bilirubin. Curr Pediatr Res 2005; 9:5-9.

10. Satrya R, EffendiH,Akhmad S and Gurnida D. Correlation between cord blood bilirubin level and incidence of hyperbilirubinemia in term newborns. Paediatr Indones 2009; 49:349-354. https://doi.org/10.14238/pi49.6.2009.349-54

11. Maisels MJ and Kring E. Length of stay, jaundice, and hospital readmission. Pediatrics 1998; 101(6):995-998. https://doi.org/10.1542/peds.101.6.995

12. Sun G, Wang Y, Liang J and Du L. Predictive value of umbilical cord blood bilirubin level for subsequent neonatal jaundice. Zhonghua Er Ke Za Zhi Chin J Pediatr 2007; 45(11):848-852.

13. Sahu S, Rebecca A, John J, Mathew AA and George AS. Cord blood albumin as a predictor of neonatal jaundice. Int J Biol Med Res 2011; 2(1):436-438.

\footnotetext{
Authors Contribution:

PS-Concept and design of the study; interpreted the results, statistically analyzed and interpreted; reviewed the literature and manuscript preparation; FCG- Concept and coordination of the overall study.

Work attributed to:

Department of Pediatrics, Nepal Medical College Teaching Hospital, Kathmandu, Nepal.

Orcid ID:

Dr. Pabitra Sapkota - (I) https://orcid.org/0000-0002-1555-0166

Source of support: Department of Pediatrics, Nepal Medical College Teaching Hospital, Kathmandu, Conflicts of Interest: None
} 